
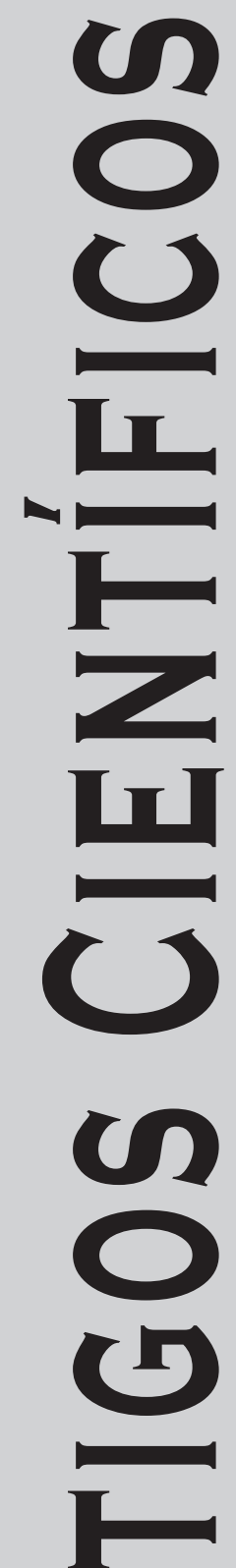
ac

Revista Música Hodie, Goiânia - V.14, 238p., n.1, 2014 


\title{
Interpretação e Performance do Texto Musical pela Hermenêutica Filosófica de Hans-Georg Gadamer
}

\author{
Danton Guilherme Oestreich (Universidade Federal do Rio Grande do Sul, Porto Alegre, RS, Brasil) \\ dantonoestreich@gmail.com
}

\begin{abstract}
Resumo: Em Verdade e Método, de 1960, Hans-Georg Gadamer buscou pela legitimação da independência epistemológica das ciências do espírito, na medida em que a experiência da verdade nestas não se limitaria ao domínio metodológico das ciências naturais. Gadamer propõe uma hermenêutica filosófica que busca revelar a estrutura prévia que opera em toda compreensão e interpretação. A interpretação do texto musical está entre estes casos que não se limitam ao domínio do método, entretanto, isto não reduz a necessidade da aplicação de um senso rigoroso na reflexão das suas possibilidades. Conceitos gadamerianos colaboram no esclarecimento destas possibilidades. A racionalidade hermenêutica é aqui apresentada como um aspecto crítico e útil ao entendimento da interpretação e performance da música referente a um texto musical.
\end{abstract}

Palavras-chave: Hermenêutica; Interpretação; Música; Performance.

Musical Text Interpretation and Performance by Hans-Georg Gadamer's Philosophical Hermeneutics

Abstract: In Truth and Method, from 1960, Hans-Georg Gadamer searched for the legitimation of human sciences epistemological independence, in that the experience of truth in those would not limit itself to the natural sciences methodological domain. Gadamer proposes a philosophical hermeneutics that looks to reveal the fore-structure that operates in all understanding and interpretation. The musical text interpretation is among those cases that do not limit itself to the method domain, however, it does not reduce the necessity of the application of a rigorous sense in the reflection of their possibilities. Gadamerian concepts collaborate in the enlightenment of these possibilities. The hermeneutic rationality is here introduced as a critical and useful aspect for the understanding of the interpretation and performance of the music referring to a musical text.

Keywords: Hermeneutics; Interpretation; Music; Performance.

\section{Introdução}

O tema deste estudo é a interpretação e performance da música que envolve o uso do texto musical, que será abordado pela perspectiva da hermenêutica - ciência que estuda a interpretação e compreensão de textos e, de modo mais geral, a linguagem como um todo. A hermenêutica tem a sua atualidade principalmente na obra do filósofo alemão HansGeorg Gadamer, ${ }^{1}$ que procurou relevar que todo entendimento possui um aspecto universal baseado na interpretação. A importância da hermenêutica no estudo da interpretação do texto musical está no fato dela se concentrar na possibilidade filosófica de entendimento do conteúdo de uma obra musical para além da sua simples configuração formal. Essa abordagem parece ser urgente na medida em que a performance musical pode carecer de significados relevantes na ausência de uma compreensão deste conteúdo. Se comunicar este conteúdo é tarefa do músico vinculado a esta tradição, e se nesta tarefa interpretação e performance se relacionam mutuamente, a clareza no entendimento das possibilidades relacionadas a tal racionalidade seria determinante à potencialização de suas reflexões. Portanto, um contínuo processo de esclarecimento do horizonte da racionalidade envolvida nestas possibilidades, seria, de fato, necessário para um melhor desenvolvimento dessa prática. Tais constatações sugerem a seguinte pergunta, que será o foco reflexivo deste artigo: no que se caracteriza a reflexão na interpretação do texto musical, tendo em vista uma racionalidade que lhe é própria e que revele significados adequados à realização em performance?

Ao reivindicar a hermenêutica gadameriana como fundamentação da reflexão que aqui procede, este estudo se liga a tradição de pensamento que busca mostrar que o enten- 
dimento da verdade se dá, também, de formas outras que aquela associada à ciência moderna dominada pelo método. A reflexão gadameriana, como será apresentado, revela que todo conceito com que operamos não é simplesmente uma construção a partir de princípios porque decorre de um acontecimento da tradição. Portanto, a consciência crítica que se pauta aqui para a reflexão do conceito é de um rigor que está além de princípios metodológicos, entendimento realmente importante à interpretação da arte em nossos tempos. Após contextualizar a hermenêutica em sua perspectiva filosófica e a sua relação com arte e estética, vamos esclarecer o horizonte histórico da tradição de interpretação musical aqui tratada, para então encontrarmos o campo de relação possível a ambas e concluir numa discussão sobre a pertinência da racionalidade hermenêutica a essa prática musical. Cabe ao presente artigo elucidar uma discussão que é relevante à atualidade desta tradição e prática musical, com as particularidades do seu modo de refletir e produzir a música.

\section{Compreensão na perspectiva hermenêutica gadameriana}

A palavra "hermenêutica" é de origem grega e está ligada simbolicamente ao deus Hermes - o que torna nela o significado de mediação de sentido inerente desde sempre. Como ciência remonta inicialmente à interpretação dos textos bíblicos e da literatura clássica grega, atingindo um novo momento de formulação durante o romantismo alemão que trouxe à tona a ideia de consciência histórica durante a modernidade. Neste momento, em que havia uma predominância geral de reflexão baseada no subjetivismo moderno e no cunho metodológico das ciências naturais, os estudos da hermenêutica também buscavam a sua legitimação por esta via.

Gadamer considera ser o objetivo do seu trabalho a busca do reconhecimento filosófico da independência epistemológica das ciências do espírito através da hermenêutica. A sua obra mais importante, Verdade e Método, questiona a racionalidade científica na sua pretensão de primazia em relação à busca da verdade diante de todas as áreas do conhecimento. Um olhar crítico perante a história revela que:

A era moderna vê o passado somente pela perspectiva do presente e deixa de apreciar a extensão na qual sua leitura das eras passadas corre o perigo de coibir verdades importantes. O valor das hermenêuticas filosóficas não é somente o de nos alentar sobre este perigo, mas sim de resgatar aquelas ideias - e verdades - tão rapidamente dispensadas em nome do progresso, ou avanço, isto é, modernidade. A fixação moderna no método ofusca formas alternativas de abordar a verdade. (LAWN, 2007, p. 47-8)

A perspectiva gadameriana, portanto, tem em vista a legitimação filosófica da busca de verdades outras, além daquelas que importam às ciências naturais, e entende que essa busca exige um procedimento próprio. A justificação desta independência está no fato da compreensão possuir uma estrutura ontológica prévia, da qual nem mesmo o método pode se ver imune, que torna a natureza da verdade muito mais ampla do que os limites que a ciência a determinou. A hermenêutica para Gadamer, desde sua origem, foi exemplo de que "compreender e interpretar textos não é um expediente reservado apenas à ciência, mas pertence claramente ao todo da experiência do homem no mundo" (GADAMER, 2012, p. 29).Uma primeira fundamentação dessa questão tem ponto de partida na exposição heideggeriana do ser, onde há uma nova reflexão crítica da filosofia tendo em vista a finitude e estrutura prévia deste. Heidegger já havia apontado para o fato de que: 
No compreender, a presença projeta seu ser para possibilidades. [...] O projetar inerente ao compreender possui a possibilidade própria de se elaborar em formas. Chamamos de interpretação essa elaboração. Nela o compreender apropria-se do que compreende. (HEIDEGGER, 2011, p. 209)

Na perspectiva da finitude a compreensão seria o próprio modo de ser da presença, logo, o problema hermenêutico estaria redefinido na medida em que havia, assim, ultrapassado o pensamento metafísico tradicional como também deixado de ser um problema de questão metodológica. Gadamer assume que esta redefinição estaria no aprofundamento do fenômeno da compreensão, onde poderia se esclarecer a relação entre verdade e método.

Para isso a tese de Verdade e Método recorreu a uma abordagem que percorre os campos da arte, da história e da linguagem, porque são estes os três ramos das ciências do espírito que mais se impõem em suas verdades à veracidade da pretensão de universalidade metodológica das ciências naturais. No retorno a uma racionalidade que se admite finita, sua tarefa se estabeleceria na busca do reconhecimento da historicidade da compreensão, vendo nisso a necessidade de um questionamento que distinga preconceitos legítimos de não-legítimos, porque são eles que representam a realidade histórica do ser. Com este posicionamento procurou restabelecer o elemento que seria de suma importância para a reflexão das ciências do espírito - a tradição, que é essencialmente conservação, tão atuante e livre quanto as duas outras forças que compõem as mudanças históricas: destruição e inovação. Lê-se em Gadamer:

A investigação das ciências do espírito não pode ver-se a si própria em oposição pura e simples ao modo como nos comportamos com respeito ao passado na nossa qualidade de seres históricos. Em nosso constante comportamento em relação ao passado, o que está realmente em questão não é o distanciamento nem a liberdade com relação ao transmitido. Ao contrário, encontramo-nos sempre inseridos na tradição. (GADAMER, 2012, p. 347)

A consequência maior disso é a distinção no modo como as ciências da natureza e as ciências do espírito estudam e compreendem o objeto em que buscam conhecimento. Na medida em que o objeto das ciências do espírito está imerso na continuidade da tradição não se deixa orientar apenas teleologicamente, bem como o padrão de conhecimento progressivo da legalidade não lhe é adequado. Essa mesma questão também exige outra consciência de posicionamento por parte do investigador, pois na medida em que a sua subjetividade não é formada independentemente da realidade histórica que lhe faz parte (que é sempre influente na antecipação de sentido que guia a compreensão) há a necessidade de reconhecer o fato de que o entendimento da tradição é determinante na capacidade compreensiva de uma subjetividade, e que a atitude de abertura à alteridade ${ }^{2}$ daquilo que constitui o seu conteúdo é sempre necessária.

Este elemento prévio que sempre opera em toda compreensão, a partir do qual e com o qual nos articulamos diante das alteridades daquilo que procuramos compreender, Gadamer denomina história efeitual - mas até que ponto podemos torná-la consciente? Para aludir a esta questão são usados dois conceitos que sugerem o espaço onde uma compreensão ocorre: situação e horizonte. Ter consciência da história efeitual é saber delimitar a situação hermenêutica em que nos encontramos, ou seja, nossas possibilidades de "ver" (compreender algo); além disso, junto à situação há o horizonte - tudo aquilo que o "campo de visão" pode abranger a partir de onde está. Assim, temos que a "elaboração da situação hermenêutica significa então a obtenção do horizonte de questionamento correto para 
as questões que se colocam frente à tradição” (GADAMER, 2012, p. 400). A história efeitual é justamente a experiência que diz haver na verdade das ciências do espírito uma interdependência entre sujeito e objeto, presente e passado, compreensão e finitude - visto que todo horizonte de questionamento só existe numa perspectiva finita que está profundamente atrelada à tradição.

Dessa forma a compreensão não poderia se dar de forma isolada, ou seja, apenas no horizonte do investigador ou apenas no horizonte do objeto; tão pouco estes horizontes possuem uma existência articulável senão na relação que se estabelece entre estes. Como Gadamer diz:

Não existe um horizonte do presente por si mesmo, assim como não existem horizontes históricos a serem conquistados. Antes, compreender é sempre um processo de fusão desses horizontes presumivelmente dados por si mesmos. [...] A vigência da tradição é o lugar onde essa fusão se dá constantemente [...]. (GADAMER, 2012, p. 404-405)

Para Gadamer essa fusão é possível porque a tradição tem a sua própria natureza de linguagem, ela nos diz algo como se fosse um tu, sendo que o "tu não é um objeto, mas se comporta em relação ao objeto” (GADAMER, 2012, p. 468), revelando assim um conteúdo de sentido na sua linguagem. O que vale nessa questão é que a experiência que se dá na relação com um tu é paralela à experiência hermenêutica diante da tradição. O atributo mais importante nessa experiência é o desenvolvimento da consciência da história efeitual, o que exige a atitude de abertura para o conteúdo de sentido que deve ser visto como o resultado próprio da compreensão da tradição. Portanto, a verdadeira experiência hermenêutica consiste em "deixar valer a tradição em suas próprias pretensões, e não no sentido de um mero reconhecimento da alteridade do passado, mas de reconhecer que ela tem algo a nos dizer" (GADAMER, 2012, p. 472).

Sendo assim, na medida em que a tradição é reconhecida como linguagem, a relação que se estabelece com ela só pode ser dialética e, consequentemente, a abertura à tradição ocorre de um modo específico: a pergunta assume uma posição privilegiada nesta abertura, pois a pergunta possui um sentido de orientação para o qual a resposta deve se dirigir se quiser ser pertinente. O próprio Gadamer assinala que "a primazia da pergunta para a essência do saber demonstra da maneira mais originária a limitação da ideia de método para o saber” (GADAMER, 2012, p. 477); já que "não há método que ensine a perguntar, a ver o que se deve questionar" (GADAMER, 2012, p. 477). Ao considerar isso percebe-se que está no poder do questionamento toda a atualidade das ciências do espírito. Note-se também que,

o fato de um texto transmitido se converter em objeto de interpretação significa que coloca uma pergunta ao intérprete. Nesse sentido, a interpretação contém sempre uma referência essencial à pergunta que nos foi dirigida. Compreender um texto quer dizer compreender essa pergunta. (GADAMER, 2012, p. 482)

A compreensão dessa pergunta é fundamental porque ela nos levará ao reencontro do porquê dos conceitos de um passado histórico (preconceitos legítimos a tal momento) e ao que talvez seja o mais importante: ao entendimento de como eles ainda nos dizem algo. Por fim, sendo que o desvelar do conteúdo de sentido do texto está à necessidade da dialética que se constrói no reconhecimento da pergunta que o texto coloca, somos nós quem temos de trazer tal conteúdo à nossa linguagem, porque é somente nela que este conteúdo poderá assumir algum sentido. Portanto, de modo geral, a produção de conhecimento para as ciências do espírito tem a estrutura dialética de pergunta e resposta e a sua lógica pró- 
pria está na abertura que a pergunta permite. Em suma é nisso que consiste a consciência da história efeitual e a fusão de horizontes, conceitos fundamentais para qualquer consideração hermenêutica.

A conclusão de Gadamer é que a fusão de horizontes existente numa compreensão só ocorre através da linguagem que é o próprio meio onde se dá a tradição e onde o sujeito e o objeto se relacionam. Com isso a hermenêutica é reintegrada à plena atualidade da reflexão contemporânea, porque a partir da universalidade do movimento da compreensão a própria hermenêutica se torna universal - algo que qualquer reflexão crítica deve ter em vista. Consequentemente, a restrição ao método fica por conta da impossibilidade de uma compreensão se dar totalmente isenta de preconceitos, como também à sua relativa parcialidade em relação ao tipo de conhecimento que pode produzir diante de um objeto na sua orientação teleológica.

Por fim, fica claro que, se idealmente a compreensão se move em direção a uma unidade de sentido perfeita que em função da nossa finitude nunca se concretiza, a compreensão só pode ser entendida como um processo formativo. Isto tem grandes consequências para as ciências do espírito não só para o entendimento interpretativo que lhe é legítimo, mas para o próprio entendimento do papel que estas cumprem dentro da tradição do conhecimento humano.

\section{Entre estética e hermenêutica, e sobre a ontologia da obra de arte}

A tese de Gadamer teve como ponto de partida a arte; - por que tamanha importância? Se a experiência da arte está entre aquelas que escapam ao domínio metodológico é porque seu fundamento vem de uma racionalidade diferente daquela que as ciências naturais elegem para si. ${ }^{3}$ Para perceber essa verdade é preciso inicialmente dar-se conta de que em determinado momento as ciências do espírito limitaram a sua reflexão a partir dos moldes das ciências naturais e questionar o que se perdeu aí. Em relação a arte, para Gadamer, isso ocorreu na autonomia e autossuficiência estética que a obra de arte adquiriu a partir da Crítica da faculdade do juízo, ${ }^{4}$ que fez com que se perdessem as considerações fundamentais relativas à tradição (aquilo que continuava a se conservar). Essa limitação que se funda na orientação teleológica ao objeto de arte, num amplo panorama, representa toda a perda das ciências do espírito ao limitarem sua reflexão ao método das ciências da natureza. Assim, seria apenas com a retomada dos fenômenos da consciência a partir da crítica fenomenológica, ao início do século XX, que a compreensão do ser estético pode renegar o absolutismo da aparência estética em favor da sua própria determinação ontológica. Para a fenomenologia a nossa percepção nunca é pura porque ela somente existe na medida em que articula aquilo que "vê"; nas palavras de Gadamer:

A percepção inclui sempre o significado. Por isso, procurar a unidade da figura estética unicamente em sua forma e em oposição ao seu conteúdo não passa de um formalismo ao avesso [...]. (GADAMER, 2012, p. 143)

Essa constatação, naturalmente, exigiria uma nova perspectiva que buscasse revelar o aspecto da finitude e da historicidade na compreensão; logo, a pergunta pela verdade da arte deveria partir do encontro que se dá entre a experiência da obra de arte e a nossa compreensão - o que leva a refletir sobre a ontologia da obra de arte.

Gadamer usa o tradicional conceito de jogo para abordar essa questão, salientando que é necessário limitar os atributos exclusivamente subjetivos que desde Kant foram-lhe 
conferidos. Vejamos então, do que se trata o conceito de jogo que para Gadamer traduz a experiência da compreensão diante da obra de arte.

Primeiramente, o que constitui o modo de ser do jogo é o movimento que é repetido em vista dele mesmo, sem ter finalidade ou intenção por si só. Isso exige a existência de um espaço lúdico que "limita-se muito mais pela disposição que determina o movimento do jogo do que por aquilo contra o que se choca" (GADAMER, 2012, p. 161). Portanto, limitações tomadas permitem o movimento do jogo manter o sentido sem impedir a sua liberdade; pelo contrário, elas são necessárias para dar forma ao movimento e permitir, assim, que o jogador abandone-se à liberdade do desenvolver-se no jogo. Aquilo que caracteriza o jogo enquanto jogo humano é "o fato de ele por assim dizer disciplinar e ordenar para si no jogo do movimento os seus movimentos de jogo, como se existissem aí metas” (GADAMER, 2010, p. 164). Logo, se esse vaivém do movimento ordenado em regras e tarefas é determinado como um comportamento, e a naturalidade do movimento no jogo está diretamente associada ao comportamento particular que as tarefas do jogo impõem, então, a finalidade do jogo é chegar à autorrepresentação desse movimento. Numa frase sintetizada: o modo de ser do jogo é autorrepresentação do movimento organizado e configurado pelas regras e tarefas que lhe são inerentes, advindas em parte da própria racionalidade humana. Logo, existe um primado do jogo face à consciência do jogador que coloca o jogo em seu sentido mais original - o de ser algo medial.

Essa autonomia, do jogo diante de todos que dele participam, é decisiva para a experiência da verdade que ocorre quando a representação torna-se um espetáculo; o que se explica no conceito de transformação em configuração: a configuração é aquilo que é repetível (e assim duradouro em sua constituição), já a transformação ocorre quando o movimento do jogo toma autonomia diante daqueles que dele participam - a mudança fundamental que deve ocorrer no jogo humano para que ele se torne um espetáculo. Perceba-se: isso sugere que nessa mudança algo acontece à nossa racionalidade, pois a arte (transformação) está num posicionamento especial da realidade (configuração), pois esta última limita-se a um horizonte de possibilidades independentes umas das outras, como também auto-excludentes, e está sempre aquém das nossas expectativas pelo fato da indeterminação do futuro permitir o excesso delas: "quando ocorre um caso especial onde um nexo de sentido se fecha e se realiza no real [...] então uma tal realidade passa a ser como um espetáculo” (GADAMER, 2012, p. 168). Portanto, é no espetáculo que encontramos a verdade da arte, que é a possibilidade de encontrarmos nele o conhecimento que se dá através da experiência da transformação no verdadeiro.

Mas que conhecimento é esse? Que verdade é essa? Para explicar, Gadamer se articula com o conceito de mimesis ao considerar que "o sentido do conhecimento da mimesis é reconhecimento" (GADAMER, 2012, p. 169); reconhecimento onde percebemos algo a mais do que já conhecíamos de antemão, o que aponta para a própria essência formativa do fenômeno da compreensão humana. Porém, o conceito de mimesis só toma essa validade quando considerado por seu aspecto cognitivo, ou seja, que o que está sendo representado é o que vale para o conhecimento, já que:

a essência da imitação consiste justamente em que vejamos naquele que representa o que é representado. A representação quer ser tão verdadeira, tão convincente, que não venhamos absolutamente a refletir sobre o fato de o representado não ser 'real'. (GADAMER, 2010, p. 18)

Portanto, é na mimesis que se encontra a proximidade da relação existente entre verdade e conhecimento na obra de arte. ${ }^{5}$ 
Após estas considerações sobre a ontologia da obra de arte podemos avaliar a relação entre estética e hermenêutica dada por Gadamer:

o ser da arte não pode ser determinado como objeto de uma consciência estética, porque, por seu lado, o comportamento estético é mais do que sabe de si mesmo. É uma parte do processo ontológico da representação e pertence essencialmente ao jogo como jogo. [...] Que consequências ontológicas tem isso? [...] O representar de um espetáculo não quer ser entendido como a satisfação de uma necessidade lúdica, mas como um entrar da própria poesia na existência. Assim, a questão é saber o que é propriamente essa obra poética [...]. (GADAMER, 2012, p. 172-173)

Isso implica na reconsideração para com várias questões. Primeiramente, significa que a inibição do absolutismo da distinção estética está na medida em que o jogo é configuração e ao mesmo tempo a configuração é jogo - o que é consequente na variabilidade das concepções interpretativas relacionadas à uma mesma obra, que não decorre somente em função das diferentes subjetividades e tão pouco é totalmente livre em si, pois a própria obra encerra possibilidades próprias de ser, se não fosse assim estaríamos negando a vinculabilidade existente entre estas diferentes concepções. Por segundo, que a unidade que existe na obra só pode ser uma unidade hermenêutica que se liga à identidade da obra; identidade que existe na medida em que a compreendemos assim, ou seja, identifico algo como algo na medida em que julgo e compreendo assim. Surge então um ponto fundamental - o artístico em uma representação "é justamente a indiferenciação entre o modo particular como uma obra é produzida e a identidade da obra por detrás da reprodução” (GADAMER, 2010, p. 170). Quando isso ocorre há um reconhecimento na representação que supera e ainda é a identidade da obra, nesse momento ímpar em que não existe mais a distinção entre a mediação da obra e ela mesma a experiência da obra é verdadeira.

Ao final da sua exposição sobre a ontologia da obra de arte Gadamer coloca que a tarefa da hermenêutica é mais ampla do que simplesmente sua tradicional delimitação à compreensão de textos, ideia que se justifica, na medida em que toda compreensão deve ser "entendida como parte do acontecimento semântico, no qual se forma e se realiza o sentido de todo o enunciado, tanto os enunciados da arte quanto os de qualquer outra tradição" (GADAMER, 2012, p. 231). Então, sendo que a hermenêutica preocupa-se mais com uma questão de conteúdo do que de aspectos formais, chegamos a um posicionamento gadameriano fundamental - a estética deve subordinar-se à hermenêutica ${ }^{6}$ - porque invariavelmente a compreensão da obra de arte passa pela mediação de sentido que é hermenêutica, que, como já foi exposto na primeira parte, ocorre na linguagem e na fusão de horizontes possíveis à tradição.

A obra de arte encontra então, a justificativa da sua importância como o ponto de partida da experiência hermenêutica às ciências do espírito na medida que

todo encontro com a linguagem da obra de arte é um encontro com um acontecimento inacabado, sendo ela mesma uma parte desse acontecimento. É isso que deve erigir contra a consciência estética e sua neutralização da questão da verdade. (GADAMER, 2012, p. 151)

Assim, a obra de arte caracteriza-se como um objeto que permite a continuidade de sua reflexão - ideia realmente própria às ciências do espírito - e, consequentemente, a consciência estética terá a ver com a realidade finita e histórica do homem e com a continuidade hermenêutica do nosso ser, ou seja, nossa autocompreensão na história. 
Sabemos então que a questão hermenêutica com a obra de arte só pode se dar na linguagem desta, que se determina como "a linguagem em função da qual a obra de arte é conservada e legada, é a linguagem que a própria obra de arte conduz, quer ela possua uma natureza linguística ou não" (GADAMER, 2010, p. 5-6). À música, basicamente, isso se refere a signos sonoros para os quais o texto musical está como referência e que possuem existência plena apenas em sua representação. Essa questão terá um desdobramento mais claro em considerações seguintes, mas, na sua generalidade, devemos entender desde já que a aparência desta linguagem é de natureza simbólica, ou seja, aponta para outra coisa que não ela mesma.

\section{Dois aspectos da interpretação do texto musical}

A interpretação do texto musical está entre estes casos que claramente não se limitam ao domínio do método, entretanto, isto não reduz a necessidade da aplicação de um senso rigoroso na reflexão das suas possibilidades. A pertinência da hermenêutica nesta questão está na retomada de uma consciência histórica perante conceitos e modos de pensar e produzir que determinaram a forma do desenvolvimento da tradição musical. O aspecto particular mais importante nisso é o entendimento de como o nosso próprio pensamento é, em grande parte, fruto de um desenvolvimento histórico e herdeiro de questões estabelecidas pela tradição. Portanto, cabe num primeiro momento esclarecer brevemente a origem de pelo menos duas perspectivas, sobretudo importantes para a interpretação musical, a saber: a tradição de intérprete, que reflete o aspecto subjetivo que é inerente a toda interpretação, e a análise musical, que reflete o aspecto objetivo da forma de uma obra.

Falar de interpretação de uma obra musical, no sentido subjetivo e especulativo, é algo que só se tornou possível durante o século XIX, grande parte em função do romantismo; pois esta concepção de interpretação está associada e é dependente do entendimento da música como um objeto estético autônomo, ou seja, uma obra musical. ${ }^{7}$ A ideia de intérprete com o qual operamos hoje também deve muito a invenção da prática do recital, ${ }^{8}$ e se esta atividade musical está originalmente associada ao romantismo, consequentemente, o entendimento das origens da ideia de intérprete da música está vinculada ao entendimento da música como arte romântica. Uma das principais perspectivas do romantismo é que aquilo que a música comunica estaria além daquilo que a linguagem verbal é capaz de comunicar; o que é relativo ao conceito de expressão que tomara grande importância naquele momento e que girava principalmente em torno dos paradigmas do eu e do sentimento. Na medida em que a proficiência técnica e expressiva assumia patamares inéditos, o intérprete se vinculava ao instrumento de uma maneira que só seria entendido nessa relação, o que nos diz muito a respeito da importância que este vínculo assumiu na tradição do recital. Uma atitude interpretativa distinta associada ao brilhantismo técnico na qual esta se demonstra, é o que caracteriza os grandes personagens desta tradição. Se a música só se emanciparia como uma "obra de arte" através desses ideais românticos, que retiravam-lhe qualquer funcionalidade ou necessidade de objetividade em relação aquilo para o qual ela seria referente, então, o conceito de expressão é de particular importância por efetivar a autonomia da linguagem musical por si só, bem como abri-la a um desenvolvimento que se focaria cada vez mais no individual e no subjetivo, justificando o aspecto de envolvimento pessoal na interpretação e a valorização da música como obra. 
A questão da emancipação do subjetivo no romantismo também resultou em inúmeras consequências formais, pois a ideia de originalidade pautou a redefinição de detalhes que antes eram atribuídos ao senso comum, ou melhor, faziam parte de uma linguagem que não buscava de modo tão intenso um desenvolvimento individual. Exemplo disso é que na progressiva separação da atividade de compositor e intérprete tornou-se necessário que a notação do texto musical adquirisse novos signos, que procuravam estabilizar aspectos expressivos da obra, o que de modo geral acarretou na disseminação da consciência da singularidade de diferentes linguagens musicais. Independentemente de ser ou não a função do texto musical representar a obra (bem como a consideração de sua capacidade para tanto) ele passou a ser entendido progressivamente como o próprio símbolo da forma sonora, dando à interpretação a responsabilidade de tradução rigorosa do seu conteúdo gráfico. Essa perspectiva de compreensão estética da forma musical foi sobretudo o que realmente surtiu um efeito prático na abordagem da música desde então, que ocorreu através da ideia de que o significado da música é inerente à sua própria relação interna, noção que se refere à plenitude de um ideal formalista de compreensão. ${ }^{9}$ É justamente essa perspectiva formalista que permitiu à interpretação tomar progressivamente ares teoréticos, com pretensões originais profundamente influenciadas pelo positivismo da ciência. ${ }^{10}$

Essa aplicação ocorre de modo mais explícito e extremado com a análise musical como a entendemos hoje, que só surgiu a partir do momento em que o ato interpretativo deixa de ser baseado em especulações genéricas (na maioria das vezes por questões extramusicais) e passa a ser aplicado a peças individuais, o que começa a acontecer por volta de 1800 quando se passa a entender a música pelo conceito de obra. Acreditava-se que a abordagem da relação interna dos sons da obra permitiria uma definição exata do que constitui a dinâmica do seu corpo sonoro. Para Cook, métodos analíticos buscam responder basicamente às seguintes questões:

Eles perguntam preferencialmente se é possível dividir a peça musical numa série de seções mais ou menos independentes. Eles perguntam como componentes da música se relacionam uns com os outros, e quais relacionamentos são mais importantes que outros. Mais especificamente, eles perguntam o quanto estes componentes derivam seus efeitos do contexto de onde estão. (COOK, 1992, p. 2) ${ }^{11}$

Questões que, portanto, possuem um direcionamento que desconsidera por completo a possibilidade da forma musical conter algum sentido que seja algo mais do que suas relações estruturais; o que só poderia ser realmente o problema numa orientação fundamentada em moldes absolutistas. Mas, distante da sua pretensão, a análise ainda não conseguiu prover nenhuma teoria capaz de se adaptar aos diversos gêneros e situações formais numa metodologia unificada. Outra limitação ocorre na medida que esta orientação não satisfaz o entendimento da forma por seu viés psicológico, ou seja, o texto musical não tem capacidade de ser, na sua totalidade, imagem daquilo que experimentamos; afinal, "qualquer transcrição, especialmente uma transcrição drasticamente simplificada como notação convencional, constitui uma interpretação do que é ouvido" (COOK, 1992, p. 225). ${ }^{12}$ Esta é uma evidência clara de que o texto musical não é uma ferramenta inicialmente destinada a qualquer tipo de tradução autônoma do seu aspecto formal, pelo contrário, ele exige que grande parte da sua compreensão se dê através da interpretação e performance, já que o som somente tem a capacidade de se tornar um signo completo quando representado. É nesse sentido, que Cook aponta para o fato de que: 
Cada sistema de notação, então, envolve seu próprio padrão de ênfase e omissão. Mas o fato de que a notação pertencente a uma dada cultura omite certas coisas não significa que estas coisas não são importantes para a música dessa cultura. O que isso significa é que quando músicos usam a notação para os propósitos que esta era destinada - quando, isto é, eles lêem ela - eles fornecem uma grande quantidade de informação que não está presente na partitura. (COOK, 1992, p. 227) ${ }^{13}$

Importa então, esclarecer o que podemos considerar por "interpretação" de uma maneira que vá além da simples reflexão formal do texto musical - em outras palavras, além do absolutismo da aparência estética em favor da determinação ontológica do objeto - em vista de sabermos pautar uma reflexão baseada numa racionalidade legítima à essa questão. Portanto, ainda que a análise musical ajude a elucidar relações e quantificações fundamentais, sendo provavelmente o argumento lógico mais forte entorno de uma objetividade estrutural da forma, não cabe considerar que tal noção diz tudo a respeito do significado e conteúdo de uma obra. Afinal, isso por si só não responde aos motivos e anseios que levaram tal forma ter tomado tal resolução; quer dizer, não revela o horizonte de questionamento prévio a partir de onde tal configuração pode surgir como uma "resposta".

Considerando isso, a interpretação não é só uma leitura analítica correta e lógica da forma, mas é em primeiro lugar a concepção de uma perspectiva de horizonte em que tal forma se justifica. O fato deste horizonte não ser tão imediato e evidente quanto a forma no seu aspecto “acabado" não significa uma importância secundária; na verdade, não poderíamos considerar que entendemos a resolução afirmativa de uma configuração senão como uma resposta satisfatória a questionamentos fundamentais e motivadores, mesmo que num âmbito estético. Assim, nota-se uma grande importância naquilo que falta objetivamente ao texto através da sua simples leitura formal, mas que trata-se de um elemento nato à natureza humana da obra em questão; ou seja, à sua configuração poética que é fruto de uma compreensão finita e histórica, justamente o ponto no qual a hermenêutica se tornará preponderante.

Após contextualizada a perspectiva hermenêutica gadameriana, é necessário notar que o entendimento da racionalidade própria à interpretação do texto musical terá de se dar na perspectiva ontológica da obra de arte, através daqueles elementos que caracterizam o conceito de jogo e, mais especificamente, numa consideração especial para com o conceito de mimesis, por ser apenas neste que a verdade e o conhecimento na arte se determinam, de modo cognitivo, como reais e articuláveis. Nesse entendimento também será necessário o esclarecimento da relação entre o conceito de mimesis e o conceito de expressão, ${ }^{14}$ isso porque, o conceito de expressão terá de ser atual à música na medida em que entendemos a prática desta última como dependente de perspectivas individuais.

Portanto, para responder a questão apresentada ao início deste estudo, será primeiramente tratada uma questão intermediária: se a mimesis como princípio maior hermenêutico convêm à prática musical aqui estudada, como isso se dá dentro das particularidades desta última?

\section{Performance musical como representação e mimesis}

Para representar é necessário conhecer as regras do jogo, ao passo que é somente assim que o movimento do jogo pode acontecer como se fosse por si só, que é justamente o que permite que ele se torne um espetáculo. Sobre isso, vale observar que é determinante que se entenda a performance como movimento da configuração da obra, tendo-se também em vista que representar é configurar este movimento. Portanto, deve-se reservar ao próprio mo- 
vimento um grau de autonomia. Essa é uma necessidade que não se pode evitar pelo fato da representação sempre ocorrer, em maior ou menor grau, sob circunstâncias diversas, tanto materiais quanto psicológicas; enquanto a isso, parece que a consciência das possibilidades extensivas de movimento, que se definem como o espaço lúdico da representação, é mais determinante para a concepção interpretativa e performática de uma obra do que propriamente um "modelo fixo" a ser seguido. Logo, a ideia que parece simplificar essas condições é justamente um comportamento que seja adequado à performance, ou seja, que se restringe e se limita às características que se justificam no espaço lúdico da obra, limitações que possibilitam ordenar e configurar o movimento dando-lhe sentido e vinculabilidade ao padrão correto. Assim, o comportamento se determina como uma força dinâmica que representa a interpretação da obra em seu conteúdo de sentido.

Consequentemente, atributos como presença e espontaneidade tornam-se requisitos fundamentais à performance, requisitos que, se voltarmos à filosofia gadameriana, estão na leveza do jogo. A leveza só pode surgir a partir do momento que passamos a conceber o ato performático através do conceito da representação, que, longe de pretender ser uma cópia daquilo que se imita, quer ser entendido como um "entrar da poesia na existência"; isto é, não se trata de cumprir à risca um plano interpretativo inflexível e impessoal, mas sim de compreendê-lo com um ato espontâneo e atual que resolva sua dinâmica discursiva numa consciência que é afirmativa à sua finitude e historicidade. Isto significa que aquilo que é configuração e aquilo que é a consciência hermenêutica do intérprete estão sempre associadas, mas o rigor interpretativo e performático que a obra exige para que o seu conteúdo de sentido transpareça, só se estabelece quando este está na linguagem estética do próprio intérprete, que se faz de maneira poética, ou seja, assumindo também o ato criativo por um fazer que é pessoal. Pois, se a necessidade do representar faz parte da essência da obra, e sendo que a vinculabilidade existe quando a representação mantém referência para com o padrão correto vindo desta, logo, o grau de validação de uma representação estaria na originalidade da vinculabilidade associada à configuração; que só pode ocorrer na medida em que consideramos a alteridade no nosso horizonte de compreensão e a nossa continuidade hermenêutica - sendo assim, a ação estética é, na verdade, uma reflexão sensível delineada por este questionamento.

Tudo isso é sumariamente importante para compreender que sendo a ocasionalidade uma particularidade especial do ato da performance, lidar com as diferenças de identidade e variação presentes numa obra reprodutiva é o único meio de considerar as potencialidades da mesma; logo, sendo que o rigor necessário para lhe dar vinculabilidade não ocorre sem a ocasionalidade, a originalidade que envolve esta última é parte essencial do ato representativo - algo que é próximo à própria natureza de desdobramento do pensamento humano diante da força do acaso. O ponto paradoxal aqui é em relação à aparente ambiguidade entre este algo configurado e algo livre ao mesmo tempo, o que na verdade se deve mais aos preconceitos da nossa atual estrutura racional, fortemente demarcada pela razão das ciências da natureza, do que a um real problema à questão - pois a arte existe como um processo formativo, tal qual a racionalidade humana em sua perspectiva geral. Portanto, decisões e escolhas que fizemos diante do ato formativo na nossa vida subjetiva resultam na nossa consciência estética, que se traduz sem dúvida em expressão, mas não num sentido autônomo - ela não pode ser considerada independente da história efeitual, tanto do objeto quanto de nós mesmos.

Assim, entender a performance musical como mimesis seria necessário na medida em que a entendemos como representação: como o modo de ser do jogo que aponta para a arte no seu sentido mais original, a saber, o poder configurador (a racionalidade) do es- 
pírito humano. A partir do ponto de vista fenomenológico, mimesis só pode ser entendida como imitação daquilo que conhecemos, logo, conhecer o desenvolvimento formal como uma configuração derivada da perspectiva de um anseio poético que é fruto de um questionamento vital, seria o único caminho à atribuição de significado àquilo que é estético dentro de possibilidades finitas e históricas. Essa linguagem é sem dúvida simbólica, pois aponta sensivelmente para aquilo que representa o todo do nosso entendimento hermenêutico diante do mundo - se revelando numa atitude mimética, que procede como uma poíesis, àquilo que é a nossa presença.

\section{Interpretação do texto musical sob a racionalidade hermenêutica}

Sendo que a legitimidade da compreensão hermenêutica pauta-se pelo rigor da reflexão existente no modo como se dá a referência ao objeto em estudo, onde a consciência da pergunta que nos foi dirigida é fundamental, então a produção do conhecimento que é característico das ciências do espírito está em entendimentos atualizadores, porque sua coerência procede através de uma racionalidade que admiti a finitude e a historicidade do homem. Assim, no caso das artes, toda produção estética passa pelo reconhecimento da consciência histórica (situação e horizonte hermenêutico) que abarca as subjetividades produtoras, porque é no reconhecimento dessa consciência que serão entendidas as perspectivas tomadas diante da obra em questão e, consequentemente, o que e como estas perspectivas significam algo à nossa atualidade. Nisso se revela a importância daquilo que a tradição tem a nos dizer, pois na medida em que transparece o dizer da tradição na nossa própria linguagem dizemos algo atual e verdadeiro porque dotado de um sentido que nos articula com o aspecto da historicidade do conhecimento e da cultura humana.

Então, dadas estas considerações, há de se concluir que a reflexão na interpretação do texto musical está indissoluvelmente ligada ao reconhecimento e articulação deste sentido, porque ele justifica muito do porquê da configuração da obra ser o que é e nos dá margem para uma representação que é poética em seu entendimento, ou seja, vê um horizonte de significados para a obra que ao mesmo tempo não deixa de revelar o todo da compreensão hermenêutica do intérprete diante do mundo. Devemos perceber que isso não exclui de modo algum o pensamento estético sobre a obra, mas essa interpretação e compreensão hermenêutica o subordina, porque, na verdade, o potencializa. O grande mérito desta racionalidade está em não limitar o desenvolvimento do ato criativo, pois é pautada num rigor que exige do intérprete a efusão criativa, sendo nela indispensável uma atitude autocrítica, que é, sem dúvida, a principal ferramenta reguladora de aprimoramento numa atitude reflexiva aonde o método não vigora.

Isso aponta para a necessidade de uma formação ampla que não tenha apenas em vista a proficiência técnica, ou se centre em ditames interpretativos que tenham uma orientação teleológica ao texto musical. A consciência estética e a sua capacidade de criar distinção àquilo que produz continua sendo algo verdadeiro e determinante quando visto como interdependente do processo de resolução formal e técnico - pois, a consciência estética por si só é uma abstração sem maiores efeitos à realidade de uma prática que nos é necessária, e do caso contrário, a representação sem esta consciência é um mero exercício técnico sem nenhum conteúdo de sentido que paute a sua essência poética. A questão é não deixarmos enganar que a consciência estética seja um fim em si mesmo, pois a continuidade incessante na articulação da forma e do conteúdo de sentido com o qual operamos só aponta para seu o aperfeiçoamento. 


\section{Notas}

1 Hans-Georg Gadamer nasceu em 1900, em Marburg, na Alemanha, e faleceu em 2002, em Heildelberg, aos 102 anos de idade. Sua principal obra, Wahrheit und Methode [Verdade e Método], foi publicada em 1960.

2 É essa abertura que constitui a experiência hermenêutica, que difere da experiência das ciências naturais porque "[...] No contexto do nascimento da ciência moderna, a validade da experiência ligou-se necessariamente à não-contradição da mesma por uma nova experiência: esse modo unilateral de conceber a experiência é o que precisa ser superado, uma vez que em Gadamer, a experiência possível na estrutura dinâmica da linguagem é sempre dialética” (RAJOBAC, 2012, p. 4).

3 Gadamer aponta que o verdadeiro fundamento das ciências do espírito está ligado ao desenvolvimento da tradição humanista, onde conceitos como Formação (Bildung), Sensus Communis, Juízo e Gosto se colocam como os conceitos básicos do humanismo (GADAMER, 2012, p. 43-4).

4 A obra de Immanuel Kant, de 1790, é um marco na história do pensamento sobre a arte; a reflexão estética, propriamente, ganhou a partir dela um nível de problematização autônoma e transcendental, sendo influente em todos os escritos posteriores. Para Gadamer o ponto de virada definitivo onde a consciência estética passa a prevalecer no entendimento das artes ocorre com Schiller: "[...] nos seus escritos estéticos [...] transformou a subjetivação radical, pela qual Kant havia justificado trancendentalmente o juízo de gosto e a sua pretensão de validade, convertendo-a de uma pressuposição metodológica em uma pressuposição de conteúdo" (GADAMER, 2012, p. 131).

5 Em 1967, no seu artigo intitulado Arte e imitação (que aborda conceitos estéticos necessários para a compreensão da arte moderna) Gadamer aprofunda a questão da relação do conceito de mimesis e a arte. Retornando até a origem do conceito na filosofia pitagórica, sugere que a mimesis, ao ser imitação de números e relações de números (apreensível intelectualmente), seja entendida como a geração de ordem e represente, assim, a ideia mais abrangente para o entendimento da obra de arte. Naturalmente, Gadamer não deixa de notar a proximidade da matemática com a música em sua origem pitagórica; essa ideia é retomada no artigo La musica y el tiempo, de 1988, onde fica subtendida a importância da relação destes dois campos para a história da música da cultura européia. É portanto, também no sentido de geração de ordem, como veremos mais adiante, que o conceito de mimesis torna-se o mais amplo e apropriado para a música.

${ }^{6}$ Em GADAMER, 2012, p. 231. O artigo Estética e Hermenêutica, de 1964, também elucida esta questão.

7 Sobre esta questão, do papel do romantismo na emancipação da música como uma "obra musical”, ver capítulo "Romantic transcendence and the separability principle" em GOEHR, 2007.

${ }^{8}$ Franz Liszt é o principal ícone em torno dessa origem, que ocorreu pela sua atividade entre os anos de 1839 a 1847. Para maiores detalhes ver BURKHOLDER, et al, 2008, p. 486; WHITTALL, 1987, p. 85-6 e GOEHR, 2007, p. 239-40.

9 Trata-se da perspectiva inicialmente apresentada por Eduard Hanslick, em O belo musical, de 1854. Vale notar que Hanslick não pune a expressão enquanto aspecto da execução musical, logo, o conceito também encontraria uma certa liberdade enquanto interpretação; quanto a este ponto ver HANSLICK, 1992, p. 97-9.

${ }^{10}$ Fubini aponta que o surgimento da musicologia na segunda metade do século XIX, no seu ideal científico, redefiniu as investigações no campo da estética da música. Ainda assim, todo o seu fundamento estaria em pressupostos estético-filosóficos do Romantismo, que teriam sido assimilados sem uma avaliação crítica, e variavam entre o conceito de música como expressão e o formalismo de Hanslick. Característica comum desses estudos é que o fator artístico estava, na maioria da vezes, fora de questão (FUBINI, 2005, p. 355-6).

11 Segue o trecho original em inglês: "They ask whether it is possible to chop up a piece of music into a series of more-or-less indepedent sections. They ask how components of the music relate to each other, and which relationships are more important than others. More specifically, they ask how far these components derive their effect from the context they are in.” Tradução nossa.

12 Segue o trecho original em inglês: "any transcription, especially a transcription as drastically simplified as conventional notation, constitutes an interpretation of what is heard.” Tradução nossa.

${ }^{13}$ Segue o trecho original em inglês: "Each system of notation, then, involves its own pattern of emphasis and omission. But the fact that the notation belonging to a given culture omits certain things does not mean that these things are not important for that culture's music. What it means is that when musicians uses the notaion for the purposes it is intended for - when, that is, they read it - they supply a great deal of information which is not actually in the score.” Tradução nossa.

14 Apesar de considerar o antigo conceito de mimesis como mais abrangente e determinante para a arte como um todo, Gadamer reconhece a importância que o conceito de expressão tem, especialmente para a estética musical, a partir da modernidade. Ver em GADAMER, 2010, p. 13. 


\section{Referências}

BURKHOLDER, J. Peter; GROUT, Donald J; PALISCA, Claude. History of western music. 7. ed. London: The Folio Society, 2008.

COOK, Nicholas. A guide to musical analysis. New York \& London: Norton \& Company, 1992.

FUBINI, Enrico. La estetica musical desde la Antigüedad hasta el siglo XX. Trad. Carlo Guillermo Pérez de Aranda. 2. ed. Madrid: Alianza Editorial, 2005

GADAMER, Hans-Georg. Verdade e Método. Trad. Flávio Paulo Meuer; revisão da tradução de Enio Paulo Giachini. 12. ed. Petrópolis, RJ: Vozes. Bragança Paulista: Editora Universitária São Francisco, 2012

Estética e hermenêutica (1964). In: Hermenêutica da Obra de Arte. Trad. Marco Antonio Casanova. São Paulo: Editora WMF Martins Fontes, 2010. p. 1-9.

. Arte e imitação (1967). In: Hermenêutica da Obra de Arte. Trad. Marco Antonio Casanova. São Paulo: Editora WMF Martins Fontes, 2010. p. 11-23.

A atualidade do belo (1974). In: Hermenêutica da Obra de Arte. Trad. Marco Antonio Casanova. São Paulo: Editora WMF Martins Fontes, 2010. p. 143-194.

. La música y el tiempo (1988). In: Arte y verdad de la palabra. Trad. José Francisco Zúñiga García. Barcelona: Paidós, 1998. p. 90-94.

GOEHR, Lydia. The Imaginary Museum of Musical Works: an essay in the philosophy of music. Revised Edition. New York \& London: Oxford University Press, 2007

HANSLICK, Eduard. O belo musical. Trad. Nicolino Simone Neto. 2. ed. Campinas: Editora da UNICAMP, 1992

HEIDEGGER, Martin. Ser e Tempo. Trad. Marcia Sá Cavalcante Shuback. 5. ed. Petrópolis, RJ: Vozes. Bragança Paulista: Editora Universitária São Francisco, 2011

LAWN, Chris. Compreender Gadamer. Trad. Hélio Magri Filho. Petrópolis, RJ: Vozes, 2007

RAJOBAC, Raimundo. Experiência hermenêutica e formação para o reconhecimento em Gadamer. In: Revista Espaço Acadêmico, n. 134, julho de 2012, p. 1-8. Disponível em: <http://periodicos.uem.br/ojs/index.php/EspacoAcademico/article/view/17683>. Acesso em: 07 nov 2013.

WHITWALL, Arnold. Romantic Music. A concise history from Schubert to Sibelius. London: Thames and Hudson, 1987.

Danton Guilherme Oestreich - Nasceu em Agudo/RS, em 1989. É Bacharel em Violão Clássico pela UFRGS. Durante os anos de 2006 a 2009 foi integrante da Orquestra Jovem UNISC, da Universidade de Santa Cruz do Sul, e durante 2009, professor de violão clássico e teoria musical do Curso de Extensão da mesma instituição. Em 2012 foi professor de violão clássico do Curso de Extensão da UFRGS. Integra o grupo de estudos MUSEF, da UFRGS, dirigido pelo Prof. Dr. Raimundo Rajobac, com estudos orientados para a área de estética e filosofia. 